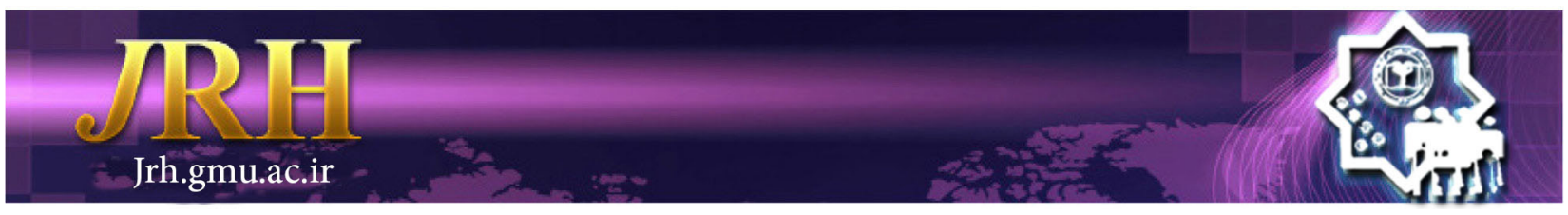

\title{
Effect of group behavioral activation on depression, anxiety and stress in adjustment: three-case study
}

\author{
Narges Zamani ${ }^{1}$, Zohreh Raeisi ${ }^{2}$, Saeed Zamani ${ }^{3}$
}

\author{
Journal of Research \& Health \\ Social Development \& Health Promotion \\ Research Center \\ Vol. 9, No.3, May \& Jun 2019 \\ Pages: 227- 235 \\ DOI: $10.29252 / j r h .9 .3 .227$ \\ Original Article
}

1. Correspondence to: Department of Health Psychology, Young Researchers and Elite Club, Hamedan Branch, Islamic Azad University, Hamedan, Iran

Email: nargeszamani@iauh.ac.ir

2. Department of Clinical Psychology, Najafabad Branch, Islamic Azad University, Najafabad, Iran

3. Department of Clinical Psychology, Young Researchers and Elite Club, Hamedan Branch, Islamic Azad University, Hamedan, Iran

Received: 15 Nov 2014

Accepted: 20 Jun 2015

How to cite this article: Zamani N, Raeisi Z, Zamani S. Effect of group behavioral activation on depression, anxiety and stress in adjustment: three-case study. $J$ Research \& Health2019; 9(3): 227- 235

\begin{abstract}
Adjustment disorders are disorders that a person cannot match with a traumatic event. People with depression, anxiety disorder and depression are susceptible to abusive behaviors, therefore, this study aimed to investigate the effect of group behavioral activation on depression, anxiety and stress in adjustment disorders by using a single case design. Three chronic patients who met DSM-5 criteria for adjustment disorders were treated according to the treatment manual of group behavioral activation therapy. The treatment outcome was measured before, during and after the treatment using depression anxiety stress scales. The results revealed this treatment in reducing the symptoms of depression, anxiety and stress was effective. The baseline scores of depression, anxiety, and stress in the first patient were 24.73, 17.54, and 28.70, respectively; the improvement rate in each of the subscales was $62 \%, 71 \%$ and $63 \%$, and the overall improvement in the three subscales was $65 \%$. For the second patient, the baseline scores of depression, anxiety, and stress were 27.73, 17.37, and 29.01, respectively; the improvement rate in each of the subscales was $54 \%, 68 \%$ and $59 \%$, and the overall improvement in the three subscales was $60 \%$. The improvement rate of the third patient was higher than that of the first and the second patients. The improvement rate in depression, anxiety, and stress was $61 \%, 60 \%$ and $67 \%$, and the overall improvement in the three subscales was $63 \%$. The overall improvement of the research variables was $62 \%$. The results of these three patients indicated that the clinical effect of group behavioral activation therapy in treating the symptoms of depression, anxiety and stress in patients with adjustment disorder and marital problems.
\end{abstract}

Keywords: Adjustment Disorders, Anxiety, Depression, Stress

\section{Introduction}

Anxiety disorders refer to a psychological state or arousal whose main features are extreme fear, hesitation, and worry [1]. Anxiety-related problems are relatively common, and about 30 to 40 percent of people in Western societies experience some disturbances associated with anxiety at some point in their lives. As a result, anxiety disorders impose a heavy burden on both the individual and community; they commonly last much longer than other psychological problems and may be as paralyzing as a physical illness [2]. Treating anxiety-related problems has costs billions of dollars, making them the most costly type of mental disorder [3].

In DSM-5, obsessive-compulsive disorder and 
post-traumatic stress disorder were categorized as the anxiety disorders [4] while in DSM5 , each of these two disorders is classified in a different diagnostic category, namely obsessive-compulsive disorder and trauma and stress-related disorders [5]. Disorders (stressor) belong to an independent and distinct diagnostic class that includes post-traumatic stress disorder, reactive attachment disorder, disinhibited social engagement disorder, acute stress disorder, and adjustment disorders [6]. In all of these disorders, the primary diagnostic criterion is experiencing a traumatic or stressful event [5].

Adjustment disorders occur when an individual cannot adapt to a stressful or traumatic event; such as the end of a romantic relationship, dismissal or several simultaneous stressful events, such as severe financial or marital problems [6]. Individuals with this disorder may have semi-clinical depressive disorder, anxiety and discomfort [5], and may be prone to risky impulsive behaviors and explosive anger [7].

The difference between these disorders and anxiety disorders is that there are no stressors in anxiety disorders, and the difference between anxiety disorders and post-traumatic stress disorder and acute stress disorder is that the stressors are very severe in the two latter cases [6]. Some of the common features of adjustment disorders are symptoms of depression, anxiety and traumatic stress or a combination of these three [5] that cause emotional and behavioral symptoms in a person within three months following the onset of these symptoms [6]. Anxiety disorders include the following groups; 1) accompanied by depressed mood: negative mood or disappointment, 2) accompanied by anxiety: nervousness, worry, irritability or separation anxiety, 3) accompanied by a combination of anxiety and depressed mood, 4) accompanied by conduct and moral problems, 5 ) accompanied by a combination of emotional and behavioral problems, such as depression and anxiety which has been manifested in behavior [5].

However, the prevalence rate of this disorder is dependent on the population studied and the methods used, but in general, the prevalence of compatibility disorders is very common and accounts for about $5 \%$ to $20 \%$ of the population [5]. Given the high prevalence of this disorder, choosing an appropriate therapeutic approach can be challenging.

Nowadays, there are many psychological treatments for depression, but few of them that have been able to prove themselves in clinical randomized trials include behavior therapy, interpersonal psychotherapy and cognitive therapy. Although all three of these therapies are effective, there are some differences in terms of efficacy and cost-effect.

Behavioral activation therapy is a type of behavioral therapy which is based on functional analysis of behavior and has been derived from the behavioral theory of depression and anxiety. The effect of this treatment has been shown in numerous studies and is superior to cognitive therapy and medication in the treatment of severe depressive patients [8].

Behavioral activation therapy is a third-wave therapy for treating mood disorders. This treatment is one of a variety of functional analytic treatments based on Skinner's psychological pattern of behavior change. This pattern is generally called behavioral analysis. This field is also part of what clinical practice analysis describes and represents one of the most effective practices in professional application of behavior analysis [5].

This therapy, as a diagnostic intervention, has proved its efficacy in dealing with anxiety and depression [8]. It should be mentioned that behavioral activation therapy is a short-term intervention and a solution-based approach which is developed based on the theory that depressed individuals often experience low levels of positive environmental reinforcement [9]. According to the behavioral activation theory, depression and anxiety symptoms appear and persist due to avoidance behaviors [10] and avoidance behaviors are effective short-term emotional regulation strategies that, in the long run, disturb the positive 
environmental outcomes in an individual's life, such as experiencing pleasant activities or creating a sense of mastery and competency [11]. In this model, therapists teach some techniques to the patients that enable them to deal with their thoughts and get engaged in their daily activities rather than evade their responsibilities [12].

The efficacy of this therapy has been confirmed by numerous studies such as Cuijpers, van Straten, Andersson and van Open [13], Ekers, Richards and Gilbody [14], Mazzucchelli, Kane and Rees [15], and Baruch, Kanter, Bow and Pfenning [16]. Chu et al. [8] confirmed the efficacy of this therapy in reducing depression and anxiety symptoms in adolescents. Hopko et al. [17] applied this therapy for anxiety, depression and stress disorders and reported its efficacy and finally, Jalili [18] showed the effect of behavioral activation therapy on marital anxiety, depression and stress.

The significance of the present study lies in the high prevalence of adjustment, anxiety, stress and depression disorders. Given that problem-solving skills play a vital role in the problems, this study aimed at investigating the effectiveness of group behavioral activation therapy on depression, anxiety and stress symptoms in patients with adjustment disorders by using a single case design. The hypothesis proposed for the present study was that group behavioral activation therapy positively influences depression, anxiety and stress symptoms in patients with adjustment disorders.

\section{Method}

The present study was conducted using a single case design in Hamadan, west of Iran.

The research population included patients with adjustment disorder who were referred to the private psychology and psychiatry clinics in spring 2014. Since the purpose of this study was to investigate the adjustment disorder, three women volunteered to participate in this study. It should be noted that inclusion and exclusion criteria were selected. The inclusion criteria were mild to moderate depression, anxiety and stress along with adjustment disorder; lack of criteria for any other mental illness and the symptoms which were not due to a common mourning or grief persisted six months after the removal of stressor and its consequences. The participants' age ranged between 22 and 26. Their emotional problems which were due to disconnecting friends or death of family members were controlled during the intervention. After describing the research objectives and appreciating the participation of patients, the Depression, Anxiety and Stress Scales (DASS) was distributed among them prior to, during and at the end of the intervention. When the baseline with a fairly constant gradient was formed for each of the three patients, the treatment was initiated (two sessions per week), and after each session, DASS was distributed among the participants to measure the treatment progress.

The DASS was used for data collection. It is a 42-item self-report scale has been developed to measure the three related negative emotional states of depression, anxiety and stress [19]. For this purpose, the participants are required to indicate the extent to which they experienced each of 42 items over the past week on a 4-point scale. Since this scale can provide a comparison of the severity of symptoms over different weeks, it can be used to evaluate the treatment progression over time.

Antony et al. [20] evaluated the factorial structure of this scale and confirmed the three factors of depression, anxiety and stress. The alpha coefficient for depression, anxiety and stress factors was 0.92, 0.97 and 0.95, respectively [20]. Moreover, the correlation coefficient was 0.48 for the relationship between depression and stress, 0.33 for the relationship between anxiety and stress and 0.28 for the relationship between anxiety and depression [20]. Samani and Jokar [21] investigated the validity and reliability of this scale in Iran. The test-retest coefficients for depression, anxiety and stress were 0.80 , 0.76 and 0.77 , respectively and the alpha coefficient for the three subscales were 0.81 , 
0.74 and 0.78 , respectively.

Each subscale includes seven items and the total score of each subscale will be obtained from adding the scores of the related items. The scores range from 0 (did not apply to me at all) to 3 (apply to me very much). Since DASS-21 is the short form of the original 42-item scale, the total score of each subscale should be doubled. The severity of the symptoms will be interpreted on five levels (normal, mild, moderate, severe and extremely severe).

In the behavioral activation therapy, the participants were requested to make a hierarchy of reinforcing activities which will then be ranked by difficulty; furthermore, participants pursue their own goals along with clinicians who employ a token economy to reinforce success in moving through the hierarchy of activities and finally, the participants would be measured prior to and after treatment using the target instruments [18].

In another form of behavioral activation therapy, patients are required to come to an understanding of the relationship between actions and emotions, in which actions are considered as the causes of emotions. An hourly self-monitoring chart is drawn to trace activities and their influence on the mood during a week. Each mood change per hour is rated from 1 to 10 with the aim of identifying the depression loops. A loop forms when a temporary method of coping, such as the temporary relief due to alcohol or other drugs, avoidance or rumination, increases depression, anxiety or stress. When dysfunctional response patterns or loops are identified, alternative coping responses will be employed to break the loop. In this method, trigger, response and coping pattern replace the trigger, response and alternative coping response. Rumination is particularly attended. It is seen as a special avoidance behavior that worsens the individual's mood. The patient is required to evaluate the rumination in terms of its functioning which, in turn, help patient better understand rumination and its emotional influences. Furthermore, the patient is persuaded to replace rumination and other possible mood worsening actions by the causes of avoidance and rumination. The therapeutic programs are as follows mood assessment, alternative response selection, acting upon alternative responses, integration of these alternatives, monitoring the results and evaluating them. The aim is to identify the relationship between actions and emotional outcomes, as well as the systematic alternation of ineffective behavior patterns with adaptive behavior patterns. Additionally, attention is paid to the quality of sleep and the context of social functions.

The training program in this study was the implementation of 8 sessions of behavioral activation group therapy, which was run weekly 2 sessions of 1.5 hours Treatment of behavioral activation was guided by the treatment guidelines developed by Desmidian, Martell, Addis and Herman- Dunn [22], which were used in this study.

In the first and second sessions, the three patients became acquainted with each other and their family life and shared their emotional suffering during their married life. During these sessions, the group members, after getting to know each other, were able to express the strengths and weaknesses of each other in decision making and criticize each other without offending which led them to ponder their decisions in life, lower their expectations of others (e.g., their partner) and acknowledge their own mistakes. After familiarizing the participants with the rules and regulations of the group, the behavioral pattern of depression, anxiety and stress were presented; afterwards, the behavioral activation therapy was introduced. At the end of the second session, the homework assignment was given to them.

In the third and fourth sessions, the behavioral activation skills functional analysis, breaking a repetitive pattern, avoidance pattern and alternative coping were taught and homework was assigned.

In the fifth and sixth sessions, an explanation about personal stressors and how depression and anxiety arise as the result of them, avoidant and active coping strategies in 
coping with stress, maladaptive coping styles and new self-care skills to increase mental health was provided for the participants and homework was assigned.

In the last two sessions, discussing the significance of social support, the ability to say no, ask for a relationship to maintain confidence, prevent recurrence, review techniques and exercises, final conclusions, and then final interview was conducted on each person. At the end of the final session, the participants were interviewed again and the DASS scale was distributed.

\section{Results}

The findings were obtained from the three patients participated in the present study. The age range of participants in the treatment was between the ages of 22 and 26, each of them were 3 women. The first patient was a 23 -yearold woman who was a third-year industrial management student at Payam Noor university. She got divorced from her husband by an uncontested divorce seven months ago and took a leave of absence of university for one semester. In the interview, she announced that she had been married for five months and got engaged one month prior to marriage. She claimed that she could not establish a good relationship with her husband's family from the very first days and her relationships with them were always unsatisfactory. Reviewing her personal history revealed that she had experienced severe depression, anxiety disorder and severe stress in new situations several times in the past few months and was treated with medication for a short time. In her family history, her mother and older sister experienced seasonal depression.

The second patient was a 25 -year-old woman with a bachelor's degree in tourism who got an uncontested divorce about 1 year and 2 months ago. She said she did not want to divorce, but at last, agreed because of the reasons such as losing contact with her husband for seven months. She as employed at a travel agency and her former spouse was her boss who is now married to one of her colleagues. She has lost her confidence since then and has always been searching for the causes of separation. She expects others to blame her husband for the broken marriage. The study of her past mental status revealed that she had a history of anxiety and separation anxiety disorder and distancing from the family members or beloved ones has always been stressful for her. She had seven sessions of short-term psychoanalytic therapy which somewhat improved her depression and anxiety; however, the symptoms recur after each incident.

The third patient was a 26-year-old woman who was an undergraduate student of psychology. As claimed by her, she was adept at problemsolving; however, her mental condition proved otherwise. Reviewing her past history revealed that she was not good at developing the relationship with the male; she had many friendship and communication experiences which always ended in separation. After each separation, she became depressed for months. Eventually, she got acquainted with her spouse in the chat room. Her husband had told her that she was good looking but he did not like her body shape and did not want to marry her. They eventually got married because of her insistence but separated after a month. From that time on, she committed suicide twice. Her family history showed that her mother suffered from somatization disorder and her sister had a history of suicide.

The three patients were selected by the inclusion criteria and received group behavioral activation therapy and the scores obtained from each session were compared with the previous one (Table 1). As can be seen from the table, behavioral activation therapy led to the overall improvement of $62 \%$ in depression, anxiety, and stress.

As indicated in Table 1, the depression scores of the first patient were severe which decreased during treatment, except for the fourth session, and the improvement rate was $62 \%$. Her anxiety score was also at the severe level, which was ultimately improved by $71 \%$, and her severe scores in stress scale were reduced to a mild level of $63 \%$, and her overall improvement rate was $65 \%$. In 
the second patient, she had severe depression, anxiety, and stress that reduced to a mild level during and after the intervention. The improvement rate in the depression variable was $54 \%, 68 \%$ in the anxiety variable and $59 \%$ in the stress variable. The third patient showed the highest improvement. The rate of improvement in depression, anxiety, and stress were $61 \%, 60 \%$, and $67 \%$ respectively. It should also be mentioned that the overall improvement of the research variables was $62 \%$.

\begin{tabular}{|c|c|c|c|c|c|c|c|c|c|c|c|c|c|}
\hline \multirow{2}{*}{ Patients } & \multirow{2}{*}{$\begin{array}{c}\text { DASS } \\
\text { subscales }\end{array}$} & \multirow{2}{*}{ Baseline } & \multicolumn{8}{|c|}{ Sessions } & \multirow{2}{*}{$\begin{array}{l}\text { Improvement } \\
\text { rate }\end{array}$} & \multirow{2}{*}{$\begin{array}{c}\text { Improvement } \\
\text { in three } \\
\text { subscales }\end{array}$} & \multirow{2}{*}{$\begin{array}{c}\text { Overall } \\
\text { improvement }\end{array}$} \\
\hline & & & 1 & 2 & 3 & 4 & 5 & 6 & 7 & 8 & & & \\
\hline \multirow{3}{*}{ First } & Depression & 24.73 & 23 & 21 & 17 & 17 & 14 & 11 & 9 & 8 & $62 \%$ & \multirow{3}{*}{$65 \%$} & \\
\hline & Anxiety & 17.54 & 18 & 16 & 13 & 13 & 12 & 9 & 8 & 6 & $71 \%$ & & \\
\hline & Stress & 28.70 & 29 & 27 & 21 & 18 & 19 & 19 & 16 & 13 & $63 \%$ & & \\
\hline \multirow{3}{*}{ Second } & Depression & 27.73 & 28 & 26 & 23 & 21 & 20 & 18 & 18 & 12 & $54 \%$ & \multirow{3}{*}{$60 \%$} & \\
\hline & Anxiety & 17.37 & 16 & 17 & 16 & 14 & 11 & 9 & 7 & 7 & $68 \%$ & & $62 \%$ \\
\hline & Stress & 29.01 & 28 & 26 & 23 & 23 & 21 & 18 & 16 & 14 & $59 \%$ & & \\
\hline \multirow{3}{*}{ Third } & Depression & 25.36 & 24 & 23 & 19 & 19 & 17 & 15 & 12 & 8 & $61 \%$ & \multirow{3}{*}{$63 \%$} & \\
\hline & Anxiety & 18.62 & 18 & 16 & 13 & 11 & 11 & 11 & 9 & 8 & $60 \%$ & & \\
\hline & Stress & 28.73 & 28 & 25 & 24 & 22 & 19 & 16 & 15 & 11 & $67 \%$ & & \\
\hline
\end{tabular}

\section{Discussion}

Many of the therapeutic guidelines for mood and anxiety disorders have been empirically confirmed. However, interventions that simultaneously deal with mood, anxiety and stress disorders are still scanty [22]. The most important duty of a therapist is to select an appropriate therapeutic approach that can respond to the needs, pain and suffering of the patients. Therefore, this study aimed at investigating the effect of group behavioral activation therapy on depression, anxiety and stress symptoms in patients with adjustment disorders and marital problems, and the results confirmed the efficacy of this therapy in reducing the severity of depression, anxiety and stress symptoms.

As to the efficacy of the group behavioral activation therapy for depression treatment, we might refer to the behavioral theory of depression which states that such therapy increases positive reinforcement [23]. The findings of the present study regarding the positive impact of this therapy on depression are in line with those of Ritschel, Ramirez, and Crughead [24], Hopko, Lejuez and Hopko [17], Dimidjian et al. [24] and Gawrysiak, Nicholas, and Hopko [25]. In Iran, Jalili [18] showed the efficacy of behavioral activation therapy on marital anxiety, depression, and stress. Furthermore, Zemestani et al. [10] concluded that behavioral activation therapy reduced depression severity in patients. However, the novelty of the present study lies in the fact that no study, except for Zemestani et al., has dealt with the comorbid depression and other disorders. The present study also dealt with patients with adjustment disorder who experience higher levels of depression, anxiety, and stress, compared with other mental disorders. In other words, adjustment disorder is comorbid with depression, anxiety, and stress.

The goal of behavioral activation in treating depression is to increase the behaviors that result in a reward from the patient (a reward for controlling depressive thoughts) that may be internal or external to help the person elevate his mood [23]. This therapy uses the strategy of breaking difficult tasks into simpler elements, and depressed people can progressively achieve success by adopting this strategy. In fact, the main objective of the treatment is to gradually change the environment, improve the mood and educate individuals to change their lifestyle and follow 
a new law in their lives [26,27]. Similar to Cuijpers, van Straten, Andersson and van Open [13], Ekers, Richards, and Gilbody [14] and Mazzucchelli, Kane and Rees [15], the present study also utilized a group therapy approach.

The results of this study regarding the effect of group behavioral activation therapy on anxiety symptoms showed that in all three patients, the level of anxiety reduced from moderate to mild which is in line with Chu et al. [8], Hopko et al. [17], Hopko, Robertson, Lejuez [28], Staley, Lawyer [29] and Armento, Hopko [30]. Regarding the effect of this therapy on the symptoms of anxiety disorder, it can be stated that although behavioral activation therapy is often used for depression treatment, the results of the aforementioned studies indicated that behavioral activation therapy can reduce the symptoms of anxiety associated with depression. Behavioral activation may reduce the symptoms in individuals suffering from stress by paying regular attention to avoidance behaviors and facilitating attitudinal behaviors that are used to increase positive responsedependent reinforcement [26].

The results of this study regarding the effect of behavioral activation therapy on stress symptoms showed that treatment reduced stress symptoms from moderate to mild levels, which could be due to training the communication skills with strangers (other group members), presenting materials required for the contextual pattern of thoughts, emotions and feelings, training the functional analysis skills, belief in breaking repetitive patterns, effective coping methods and talking about personal stressors, social support and assertiveness training.

There was no research on the efficacy of this treatment for stress disorder which shows novelty of this study which is directly related to depression and anxiety, because anxiety and depression commonly appear after severe stress [3]. In fact, they are comorbid disorders.

Another novelty of this study is that behavioral activation therapy was practiced in the group format and the interaction in similar groups reduces the stress and pain caused by the problems.
The findings of this study might have practical implications for improving the mental health of individuals with marital problems and prevention of mood and stress disorders. One of the implications of these findings is that behavioral activation therapy might be a useful and cost-effective group therapy, and since this treatment protocol is designed in eight sessions, it can be considered as a shortterm treatment that might result in meaningful clinical outcomes.

This finding primarily indicates the efficacy of behavioral activation therapy on anxiety, depression, and stress, which is consistent with the results of the studies mentioned above. To interpret the findings of the present study, it is necessary to consider the limitations such as the small sample size, lack of follow-up study and the lack of a control group. Therefore, other researchers are recommended to replicate the same study with a larger sample size or using an experimental design with the control group.

\section{Conclusion}

This study showed that group behavioral activation therapy is effective on depression, anxiety and stress symptoms among patients with adjustment disorder and marital problems. Considering the effect of behavioral activation in improving mental health of women with marital problems, this treatment can be included as a complementary program in patients' treatment.

\section{Acknowledgements}

The authors would like to express their sincere appreciation to the participants and all their colleagues in Welfare Organization.

\section{Contribution}

Study design: NZ, SZ

Data collection and analysis: NZ, ZR

Manuscript preparation: NZ, ZR

\section{Conflict of Interests}

"The authors declared that they have no competing interests". 


\section{Funding}

The author (s) received no financial support for the research, authorship and/or publication of this article.

\section{References}

1- Zamani N, Habibi M, Darvishi M. Compare the effectiveness dialectical behavior therapy and cognitivebehavioral group therapy in reducing depression in mothers of children with disabilities. Journal of Arak University of Medical Sciences2015; 18(1): 32-42.

2- Sadock BJ, Sadock AS, Sadock PRB. Kaplan and sadock's comprehensive text book of psychiatry. USA, Philadelphia: Lippincott Williams \& Wilkins (LWW) pub; 2017.

3-Zamani N, Zamani S, Habibi M, Abedini S. Comparison in stress of caring mothers of children with developmental, external and internal disorders and normal children. Journal of Research and Health2017; 7(2): 688- 94.

4- American Psychiatric Association, Diagnostic and Statistical Manual of Mental Disorders 5 edition,(3rd ed. revised). Washington DC: American Psychologist; 2000.

5- American Psychiatric Association, Diagnostic and Statistical Manual of Mental Disorders 5 edition, (Dsm-

5). New York: American Psychologist; 2013.

6- Ganji M. Abnormal psychology based on DSM-5. Tehran: Savalane pub; 2013.

7- Jamilian H, Malekirad A, Farhadi M, Habibi M, Zamani N. Effectiveness of group dialectical behavior therapy (based on core distress tolerance and emotion regulation components) on expulsive anger and impulsive behaviors. Glob J Health Sci2014; 6(7): 116-23.

8- Chu BC, Colognori D, Weissman AS, Bannon K. An initial description and pilot of group behavioral activation therapy for anxious and depressed youth. Cogn Behav Pract2009; 16(4): 408-19.

9- Dimidjian S, Martell CR, Addis ME, Herman- Dunn

R. Behavioral activation for depression. In: Barlow DH, ed. Clinical handbook of psychological disorders, 4th ed. A step-by-step treatment manual. New York: Guilford press; 2008.

10- Zemestani M, Davoudi I, Mehrabizadeh-Honarmand M, Zargar Y. Effectiveness of group behavioral activation on depression, anxiety and rumination in patients with depression and anxiety. Journal of Clinical Psychology2014; 5(4): 73-85.

11- Ritschel LA, Ramirez C, Crughead WE. Behavioral activation for depressed teens: A pilot study. Cog Behav Pract2011; 18(2): 281-99.

12-Martell CR, Dimidjian S, Herman-Dunn R. Behavioral activation for depression: a clinician's guide. New York: Guilford press; 2010.

13- Cuijpers P, Van Straten A, Andersson G, Van Oppen
P. Psychotherapy for depression in adults: a metaanalysis of comparative outcome studies. J Consult Clin Psychol2008; 76(6): 909-922.

14- Ekers D, Richards D, Gilbody S. A meta-analysis of randomized trials of behavioral treatments of depression. Psychol Med2008; 38(5): 611-23.

15- Mazzucchelli T, Kane R, Rees C. Behavioral activation treatments for adults: A meta-analysis and review. Clin Psychol (New York)2009; 16(4): 383-411. 16- Baruch DE, Kanter JW, Bow M, Pfenning SL. Improving homework compliance in career counseling with a behavioral activation functional assessment procedure: A pilot study. Cog Behav Prac2011; 18(2): 256-66.

17- Hopko DR, Lejuez CW, Hopko SD. Behavioral activation as an intervention for co-existent depressive and anxiety symptoms. Clin Case Stud2004; 3(1): 37-48. 18- Jalili A. Effectiveness of group behavioral activation on decreasing of depression symptoms and effect of this treatment decreasing of dysfunctional attitudes. [dissertation]. Tehran: Tehran university of medical sciences 2006.

19- Lovibond PF, Lovibond SH. The structure of negative emotional states: comparison of the depression anxiety stress scale (DASS) with the beck depression and anxiety inventories. Behav Res Ther1995; 33(3): 335-43.

20-Antony MM, Bieling PJ, Cox BJ, Enns MW, Swinton RP. Psychometric properties of the 42-item and 21-item version of the depression anxiety stress scale in clinical group and a community sample. Psychol Assess 1998; 10(2): 176-81.

21- Samani S, Jokar B. Reliability and validity of depression, anxiety, and stress scale-DASS. Journal of Social Science and Humanistic2007; 26(3): 65-75.

22- Houghton S, Curran J, Ekers D. Behavioural activation in the treatment of depression. Mental Health Practice2011; 14(7); 18-23.

23- Leahy RL, Holland SJ, McGinn LK. Treatment plans and interventions for depression and anxiety disorders. 2nd ed. New York: Guilford press; 2012.

24- Dimidjian S, Hollon SD, Dobson KS, et al. Randomized trial of behavioral activation, cognitive therapy, and antidepressant medication in the acute treatment of adults with major depression. $J$ Consult Clin Psychol2006; 74(4): 658-70.

25- Gawrysiak M, Nicholas C, Hopko D. Behavioral activation for moderately depressed university students: Randomized controlled trial. J Couns Psychol2009; 56(3): 468-75.

26- Zamani N, Zamani S, Habibi M. A comparison between the effectiveness of dialectical and cognitive behavioral therapy on the mental health of mother. J Research \& Health2019; 9(1): 53- 61. 
27- Martell C, Addis M, Dimidjian S. Finding the action in behavioral activation: The search for empirically supported interventions and mechanisms of change. In: Hayes SC, Follette VM, Linehan MM, editors. Mindfulness and acceptance: Expanding the cognitivebehavioral tradition. New York, NY: Guilford press; 2004. pp: 152-167.

28- Hopko DR, Robertson SMC, Lejuez CW. Behavioral activation for anxiety disorders. Behav Anal Today2006;
7(2): 212-32.

29- Staley CS, Lawyer SR. Behavioral activation and CBT as an intervention for coexistent major depression and social phobia for a biracial client with diabetes. Clin Case Stud2010; 9(1): 63-73.

30- Armento MEA, Hopko DR. Behavioral activation of a breast cancer patient with co-existent major depression and generalized anxiety disorder. Clin Case Stud2009; 8(1): 25-37.

\footnotetext{
Copyright $\subset$ 2016 ASP Ins. This open-access article is published under the terms of the Creative Commons Attribution-NonCommercial 4.0 International License which permits Share (copy and redistribute the material in any medium or format) and Adapt (remix, transform, and build upon the material) under the Attribution-NonCommercial terms.
} 